IZA DP No. 4545

Incentive Effects on Risk Attitude in Small Probability Prospects

Mathieu Lefebvre

Ferdinand M. Vieider

Marie Claire Villeval

November 2009 


\title{
Incentive Effects on Risk Attitude in Small Probability Prospects
}

\author{
Mathieu Lefebvre \\ University of Liège, CREPP \\ and GATE
}

Ferdinand M. Vieider

University of Lyon, CNRS-GATE

and DIW Berlin

Marie Claire Villeval

University of Lyon, CNRS-GATE, CCP, Aarhus University and IZA

Discussion Paper No. 4545
November 2009

IZA

P.O. Box 7240

53072 Bonn

Germany

Phone: +49-228-3894-0

Fax: +49-228-3894-180

E-mail: iza@iza.org

Any opinions expressed here are those of the author(s) and not those of IZA. Research published in this series may include views on policy, but the institute itself takes no institutional policy positions.

The Institute for the Study of Labor (IZA) in Bonn is a local and virtual international research center and a place of communication between science, politics and business. IZA is an independent nonprofit organization supported by Deutsche Post Foundation. The center is associated with the University of Bonn and offers a stimulating research environment through its international network, workshops and conferences, data service, project support, research visits and doctoral program. IZA engages in (i) original and internationally competitive research in all fields of labor economics, (ii) development of policy concepts, and (iii) dissemination of research results and concepts to the interested public.

IZA Discussion Papers often represent preliminary work and are circulated to encourage discussion. Citation of such a paper should account for its provisional character. A revised version may be available directly from the author. 
IZA Discussion Paper No. 4545

November 2009

\section{ABSTRACT}

\section{Incentive Effects on Risk Attitude in Small Probability Prospects*}

Most studies on the role of incentives on risk attitude report data obtained from within-subject experimental investigations. This may however raise an issue of sequentiality of effects as later choices may be influenced by earlier ones. This paper reports instead between-subject results on the effect of monetary stakes on risk attitudes for small probability prospects in a laboratory experiment. Under low stakes, we find the typical risk seeking behavior for small probabilities predicted by the prospect theory. But under high stakes, we provide some evidence that risk seeking behavior is dramatically reduced. This could suggest that utility is not consistently concave over the outcome space, but rather contains a convex section for very small amounts.

JEL Classification: C91, D81, D89

Keywords: risk attitude, incentives, decision, experiment

Corresponding author:

Marie Claire Villeval

GATE (Groupe d'Analyse et de Théorie Economique)

CNRS - University of Lyon

93, Chemin de Mouilles

69130 Ecully

France

E-mail: villeval@gate.cnrs.fr

\footnotetext{
* The authors thank S. Ferriol for programming the experiment. Financial support from the EMIR program of the French National Agency for Research (ANR) is gratefully acknowledged (BLAN073_185547).
} 


\section{INTRODUCTION}

Notwithstanding a large research effort in individual decision making under risk, certain voids remain in our understanding of risk attitudes. One issue that has been hotly debated in the literature is the effect—and for that matter, the necessity—of the provision of monetary incentives when studying risk attitudes. As for many other economic decisions (Camerer \& Hogarth, 1999; Johansson-Stenman, Mahmud, \& Martinsson, 2005; Kocher, Martinsson, \& Visser, 2008), the effect of incentives is a potentially contentious issue, since many of the traditional findings on risk attitudes have been obtained with hypothetical payoffs. After many years of heated debate, a consensus on these issues seems to be emerging. Indeed, financial incentives are generally thought to leave the qualitative findings obtained with hypothetical studies intact (Battalio, Kagel, \& Jiranyakul, 1990). Quantitatively however, incentives seem to matter inasmuch as higher stakes increase risk aversion (Astrebo, Mata, \& Santos-Pinto, 2009; Binswanger, 1980; Kachelmeier \& Shahata, 1992). Also, while the size of real stakes matters, so do the nominal stakes in hypothetical choices (Kühberger, SchulteMecklenberg, \& Perner , 2002; Holt \& Laury, 2002; Laury \& Holt, 2005).

Even though the studies cited above have accumulated a substantial (and generally coherent) view on the issue, some methodological doubts remain. Indeed, although the studies cited used different methodologies for the elicitation of risk attitudes and thus proved the stability of the finding, they all report data obtained from within-subject investigations of the issue. While within-subject investigations are statistically powerful and avoid potential confounds, they also pose an issue of sequentiality of effects as later choices may be influenced by earlier ones. For instance, Kachelmeier \& Shehata remark how "the transparent manipulation of prize level may have acted as a cue to subjects that their responses should change” (p. 1131). Read (2005) criticizes Holt \& Laury (2002) for repeatedly telling subjects that certain choices were hypothetical, and especially for emphasizing the contrast of those 
hypothetical choices to preceding and following real choices. More generally, the withinsubject method may suffer from experimenter demand effects, whereby subjects try to conform to the presumed expectations of the experimenter (Minor, 1970; Sawyer, 1975). Even in the absence of a motivation to please the experimenter, variations could be introduced by issues of sensitization (Greenwald, 1978).

To the best of our knowledge, no systematic investigation of between-subject effects of different stakes on risk attitude exists. This is all the more surprising since the papers cited above seem all to have some between-subject data that could be used for such tests. However, no statistics regarding between-subject results are explicitly reported in those papers. This may in part be due to the higher number of subjects needed in between-subject designs to reach a level of statistical power that is comparable to within-subject designs. Indeed, by removing subject variance from the error term, within-subject tests are statistically much more powerful than between-subject designs. This means that not only a between-subject design will need $n \times k$ the subjects of a within-subject design with $k$ subjects ( where $n$ is the number of treatments), but the within-subject design using $k$ subjects will still be much more powerful (Greenwald, 1978). This may in part explain the recurrence to within-subject designs, inasmuch as obtaining between-subject data on the effect of high stakes can quickly become very expensive. Even though we do not agree with certain methodological arguments that consider between-subject data the gold standard to which all other results need to be compared (see e.g. Poulton, 1973), we think that such data may in some cases reveal interesting new insights.

We want to add to the existing literature by presenting some between-subject results on the effect of financial stakes on risk attitudes for small probability prospects. Even though our attention is restricted to small probabilities for budgetary reasons, the changes in stakes are substantial, ranging from prizes of $€ 4$ (\$6) to prizes of $€ 100$ (\$150). Also, we collected 
data using different methodologies, ranging from certainty equivalents to buying prices (amounts to invest). While finding the typical pattern of risk seeking for small probability prospects under low monetary stakes, we show that such risk seeking is substantially reduced under high stakes.

\section{THE EXPERIMENT}

\subsection{Method}

Subjects. The experiment has been conducted at GATE (Groupe d'Analyse et de Théorie Economique), at the University of Lyon, France. 78 undergraduate students from the local engineering and business schools were recruited using the ORSEE software (Greiner, 2004). $64 \%$ of subjects were female, the average age was 22 . Four sessions were run, with 20 subjects in two of them and 19 subjects in the other two. On average the subjects earned $€ 22.58$, including a show-up fee of $€ 5$, for an experiment lasting less than 30 minutes.

Tasks. The experiment was computerized, using the REGATE software (Zeiliger, 2000). Subjects absolved several tasks in the course of an experiment on lottery preferences and probability representations that is described in Lefebvre, Vieider, \& Villeval (2009). Since different probability representations were found to have no significant effect, we will not further discuss how probabilities were represented. Two different tasks relevant for the present paper were used. First, a context-free neutral task was used to elicit certainty equivalents for a binary lottery giving a 10\% probability of winning a prize and a complementary probability of winning nothing. Certainty equivalents were elicited through a list of 26 choices (see Appendix).

Next, subjects' willingness to invest into a risky and potentially lucrative project was explored. The investment task was presented as the decision to invest or not in a clean energy 
project. Subjects were given an initial endowment, and the amount subjects were willing to invest was then elicited through a list of 12 choices. In the investment task, subjects were randomly assigned one of three probabilities of investment success ranging between $5.9 \%$ and $7 \%$. Since this was done for both the low and high stakes conditions, and since ratios of elicited values to expected value $(E V)$ are used for the analysis, this small variation in probabilities does not affect the results presented.

Incentives. A show-up fee of $€ 5$ was provided to all subjects. Subjects were assigned to either a Low-Stakes or a High-Stakes condition. In the Low-Stakes condition, the prizes were $€ 10$ (\$15) for the neutral task, and $€ 4$ (\$6) for the investment task, with the latter to be financed out of an initial endowment of $€ 0.60$ (90థ). In the High-Stakes condition, all amounts were increased by a factor of 10 , implying prizes of $€ 100$ (\$150) and $€ 40$ (\$60) for the neutral and investment tasks, respectively.

Encoding. The certainty equivalent $(C E)$ and the willingness-to-pay for investment (WTP) were calculated as the mean between the two amounts for which subjects switched from the prospect to the certain amount (in the case of CE), or from the certain amount to the prospect (in the case of WTP).

Hypotheses. Given that small probabilities are used throughout, we expect that subjects will on average be risk seeking as predicted by prospect theory (Abdellaoui, 2000; Bleichrodt \& Pinto, 2000; van de Kuilen et al., 2006; Wu \& Gonzalez, 1996). Indeed, subjects are generally found to overweight small probabilities of winning, so that we may expect CEs and WTPs to lie above the expected value. Finally and most importantly, we expect that risk seeking will be reduced significantly in the High-Stakes condition as compared to the Low-Stakes condition. 


\subsection{Results}

Neutral task. 6 subjects were dropped from the sample because they switched multiple times between the sure amount and the prospect. Those subjects are dropped since it is not clear what their CE is. Under low stakes, we find the typical behavior of risk seeking for small probabilities predicted by prospect theory, with a mean ratio of the CE to EV of 1.66. We thus strongly reject the hypothesis that subjects are expected value maximizers for low stakes $(t(39)=8.53, p<0.001$; all $p$-values are two-sided) in favor of the hypothesis that subjects are risk seeking. At the individual level, only two subjects out of 40 can be classified as risk averse, three as risk neutral, and the remaining 35 as risk seeking. Data on the frequency distribution of risk attitudes are displayed in Table 1.

Table 1: Classification of subjects in terms of risk attitude

Tasks Condition Distribution of risk attitudes

\begin{tabular}{llcccc}
\cline { 3 - 5 } & & $\begin{array}{c}\text { Risk } \\
\text { averse }\end{array}$ & $\begin{array}{c}\text { Risk } \\
\text { neutral }\end{array}$ & $\begin{array}{c}\text { Risk } \\
\text { seeking }\end{array}$ & Total \\
\hline \multirow{2}{*}{ Neutral task } & Low stakes & $2(5.00)$ & $3(7.50)$ & $35(87.50)$ & $40(100)$ \\
& High stakes & $14(43.75)$ & $6(18.75)$ & $12(37.50)$ & $32(100)$ \\
& Low stakes & $5(12.50)$ & $2(5.00)$ & $33(82.50)$ & $40(100)$ \\
Investment task & High stakes & $9(26.47)$ & $2(5.88)$ & $23(67.65)$ & $34(100)$ \\
\hline
\end{tabular}

Note: Relative frequencies in parentheses.

This picture changes when we look at the High-Stakes condition. On average, subject are now roughly risk neutral with an average ratio of CE to EV of 0.96. Indeed, the hypothesis of risk neutrality can now not be rejected $(t(31)=-0.44, p=0.67)$. At the individual level, 14 subjects can now be classified as risk averse, six as risk neutral, and 12 as risk seeking. We thus confirm that in the High-Stakes condition subjects are on average significantly less risk 
seeking than in the Low-Stakes condition $(z=4.74, p<0.001$, Mann-Whitney test). Though women are on average slightly less risk seeking than men, this difference is neither significant for the overall data nor within either of the two incentive conditions.

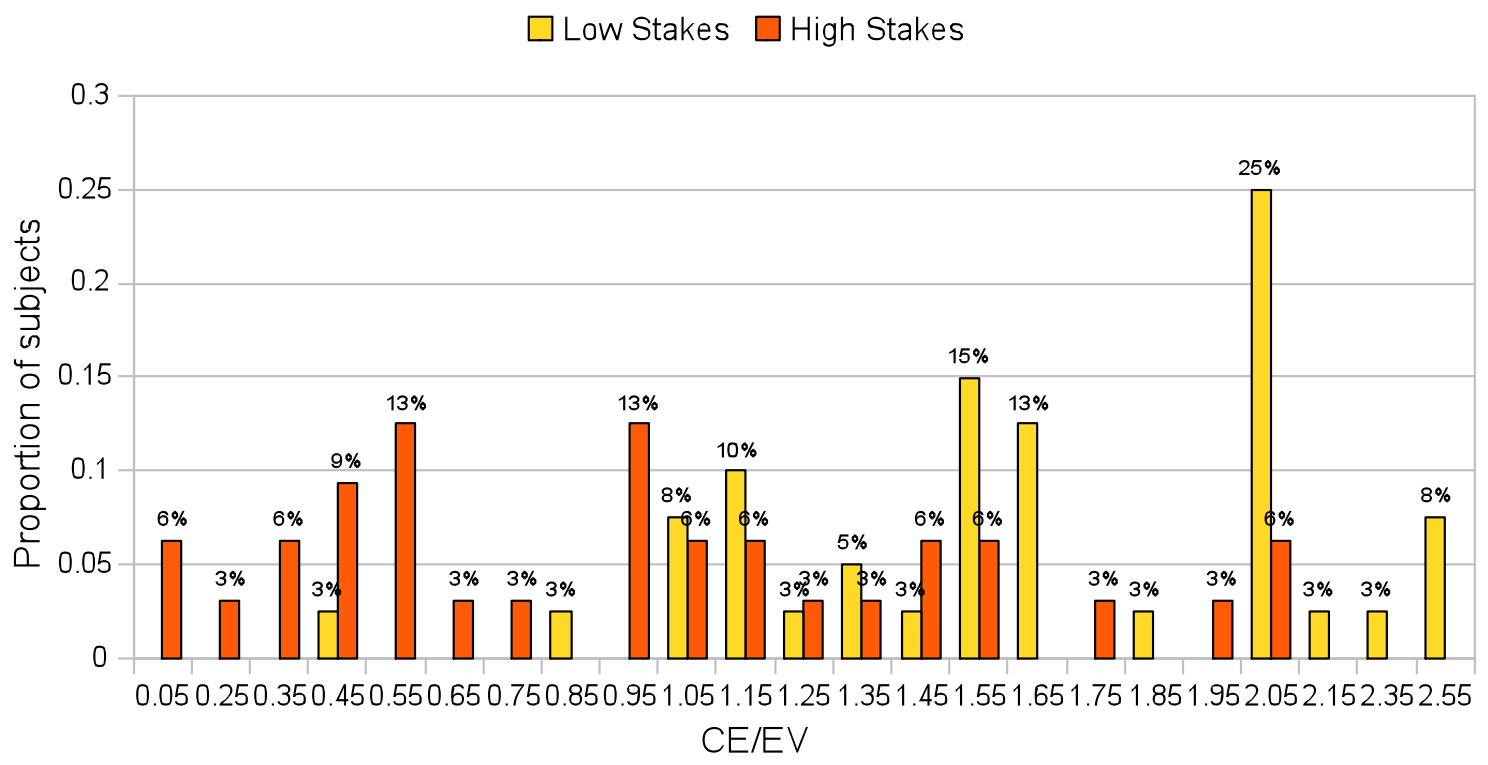

Figure 1: Ratio of CE to EV for Low and High Stakes

Investment Task. 6 subjects were eliminated because they switched several times between investing and not investing. Those subjects are dropped since it is not clear what their WTP is. Again, we find the typical behavior of risk seeking for low stakes, with a mean ratio of WTP to EV equal to 1.88 . We again easily reject the null hypothesis of risk neutrality $(t(37)=6.05$, $p<0.001$ ). At the individual level, five subjects can be classified as risk averse, two as risk neutral, and 33 as risk seeking (see Table 1). Under high stakes we now also find risk seeking, with the mean WTP on EV ratio equal to 1.52. This time we reject the null hypothesis of risk neutrality also for high stakes $(t(33)=3.31, p=0.002)$. At the individual level, we can classify nine subjects as risk averse, two as risk neutral, and 23 as risk seeking. As hypothesized, subjects in the High-Stakes condition are on average less risk seeking than 
subjects in the Low-Stakes condition $(z=1.93, p=0.05$; Mann-Whitney test) (see also Figure 2). Just as for the neutral task, no significant gender differences are present.

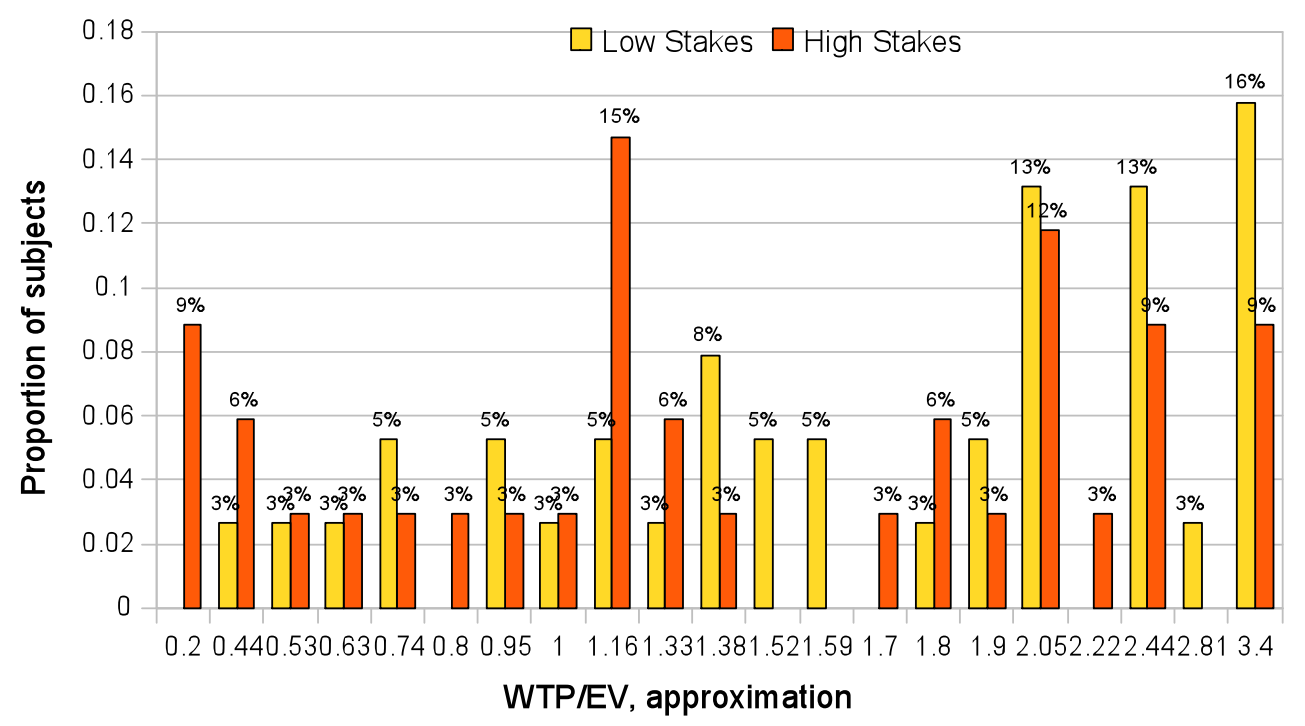

Figure 2: Proportion of subjects by WTP/EV ratio. Approximations of WTP/EV were used to condensate findings; this was necessary since different probability levels produced small difference in EV that resulted in a multiplicity of slightly different WTP/EV ratios.

\section{DISCUSSION}

Our between-subject data confirm previous findings in the literature according to which individuals become more risk averse — or in our case less risk seeking-when high stakes are involved. This effect is indeed very strong for a neutral task in which CEs are elicited. When smaller stakes are used in an investment task, the effect is found also for willingness to invest into a potentially profitable project. However, the effect is significantly less strong in the latter case $(\mathrm{Z}=1.49, p=0.06$, Fisher's $\mathrm{z}$ test $)$.

Subjects are generally found to be risk seeking for small probability prospects as would be predicted by the overweighting of small probabilities generally found in the literature (Abdellaoui, 2000; Bleichrodt \& Pinto, 2000; van de Kuilen, Wakker, \& Zou, 2006; Wu \& Gonzalez, 1996). While subjects become risk neutral under high incentives for the 
neutral task, they remain risk seeking for the investment task. This difference between the neutral and the investment tasks may potentially be driven by either of two factors: the introduction of context into the decision (people may be more prone to risk-seeking in a context of investment in an environmental good), or the elicitation of willingness-to-pay instead of certain equivalents. Disentangling these two explanations is beyond the scope of this paper but may be an interesting topic for future research.

Assuming prospect theory as a descriptive model of choice, the difference between low and high stakes can be explained with attitudes towards outcomes, since probability weighting is a purely probabilistic matter and should not change between low and high stakes (see however Bradley, 2003, on difficulties with this separation). This is however somewhat troubling, since it is generally assumed that utility should be linear for such small amounts (Abdellaoui, Bleichrodt, \& L'Haridon, 2008; Booij \& van de Kuilen, 2009). One potential explanation is that the low income of our subject population of students implies utility curvature already for relatively small gains. A potential alternative explanation would be that utility is not consistently concave over the outcome space, but rather contains a convex section for very small amounts (Bosch-Domènech \& Silvestre, 1999; Markowitz, 1952).

According to this peanut effect (Prelec \& Loewenstein, 1991; Weber \& Chapman, 2005), the extreme risk seeking found for small amounts would be the result of both overweighing of small probabilities and an increasing marginal utility of money for small amounts of money. Indeed, the latter would predict that small amounts of money that are offered for sure in our two tasks are attributed very low utility, which implies extreme risk seeking in the Low-Stakes condition. This approach would explain the extreme difference in risk seeking behavior in our neutral task not through a rapidly decreasing marginal utility of money, but rather through a combination of initially increasing and subsequently decreasing marginal utility (in addition to the overweighting of small probabilities). Notice how this 
conceptual framework may also explain why we find a weaker effect of monetary stakes in the investment task. Indeed, sure amounts used in the latter are even smaller and may thus be undervalued in both conditions, resulting in persisting risk seeking in the High-Stakes condition.

\section{CONCLUSION}

The importance of monetary stakes for risk attitude is an important issue in the decision making literature. Even though several studies investigating the effect of high monetary stakes on risk attitude exist, data reported are generally obtained by means of within-subject designs, and doubts have been aired about the soundness of that approach. In this paper we test instead the effect of high monetary stakes for small probability prospects in a betweensubject design. While finding the typical pattern of risk seeking for small probability prospects under low stakes, such risk seeking is found to be substantially reduced under high stakes. This finding may create problems for prospect theory as it stands, but could be explained either by subject pool effects, or by a peanut effect, according to which the utility curve may have a convex section for low gain amounts. 


\section{APPENDIX}

\section{Neutral Task (High stakes):}

Below you are asked to choose repeatedly between different certain amounts and a draw from an urn containing $\mathbf{1}$ red ball(s) and $\mathbf{9}$ black balls. The prize for drawing a red ball from the urn is EUR 100 .

In the payoff determination phase, one of your choices below will be selected at random. In case you have chosen the sure amount in the selected choice, you will simply be paid that amount. In case you have chosen the extraction, one ball will be extracted from the urn: if the ball is red, you will be paid EUR 10p; if the ball is black you will obtain nothing.
I choose EUR0.5 for sure
I choose EURI for sure
I choose EUR2 for sure
I choose EUR3 for sure
I choose EUR4 for sure
I choose EUR5 for sure
I choose EUR6 for sure
I choose EUR7 for sure
I choose EUR8 for sure
I choose EUR9 for sure
I choose EURI0 for sure
I choose EURIl for sure
I choose EUR12 for sure
I choose EUR13 for sure
I choose EURI4 for sure
I choose EUR15 for sure
I choose EUR16 for sure
I choose EURI7 for sure
I choose EUR18 for sure
I choose EUR19 for sure
I choose EUR20 for sure
I choose EUR21 for sure
I choose EUR22 for sure
I choose EUR23 for sure
I choose EUR24 for sure
I choose EUR25 for sure

I choose the extraction

I choose the extraction

I choose the extraction

I choose the extraction

I choose the extraction

I choose the extraction

I choose the extraction

I choose the extraction

I choose the extraction

I choose the extraction

I choose the extraction

I choose the extraction

I choose the extraction

I choose the extraction

I choose the extraction

I choose the extraction

I choose the extraction

I choose the extraction

I I choose the extraction

I choose the extraction

I choose the extraction

I choose the extraction

I choose the extraction

I choose the extraction

I choose the extraction

I choose the extraction 


\section{Investment Task: Choice List}

You are now given a EUR 6 endowment.

You must ow decide whether to keep that money or use it to make a potentially lucrative investment. Imagine this situation: a colleague of yours has offered you the opportunity to buy a share in a new clean energy project. Given the massive demand by governments for renewable energy, this investment offers a payoff of EUR40

However, there is a chance that your technology will be abandoned in favor of a more promising technology, You know that there are 1000 alternative projects being implemented, of which 59 will finally be pursued and hence produce their promised payoffs.

Please indicate in the list below how much of your EUR 6 endowment, if any, is the maximum amount you would be willing to invest. One of your choices will be selected for real play. If you have chosen not to invest, you keep your EUR6. I you have chosen to invest, the price will be deduced from your endowment and the investment will be played out. If your investment is successful, you get EUR40 plus what remains of your endowment, if not you obtain only what remains of your endowment.

$\begin{array}{ll}\text { I choose to invest in the project for EUR0.5 } & \text { I prefer not to invest } \\ \text { I choose to invest in the project for EUR1 } & \text { I prefer not to invest } \\ \text { I choose to invest in the project for EUR1.5 } & \text { I prefer not to invest } \\ \text { I choose to invest in the project for EUR2 } & \text { I prefer not to invest } \\ \text { I choose to invest in the project for EUR2.5 } & \text { I prefer not to invest } \\ \text { I choose to invest in the project for EUR3 } & \text { I prefer not to invest } \\ \text { I choose to invest in the project for EUR3.5 } & \text { I prefer not to invest } \\ \text { I choose to invest in the project for EUR4 } & \text { I prefer not to invest } \\ \text { I choose to invest in the project for EUR4.5 } & \text { I prefer not to invest } \\ \text { I choose to invest in the project for EUR5 } & \text { I prefer not to invest } \\ \text { I choose to invest in the project for EUR5.5 } & 0 \text { I prefer not to invest } \\ \text { I choose to invest in the project for EUR6 } & 0 \text { I prefer not to invest }\end{array}$




\section{REFERENCES}

Abdellaoui, Mohammed (2000). Parameter-Free Elicitation of Utility and Probability Weighting Functions. Management Science 46(1), 1497-1512.

Abdellaoui, Mohammed, Han Bleichrodt, \& Olivier L'Haridon (2008). A Tractable Method to Measure Utility and Loss Aversion under Prospect Theory. Journal of Risk and Uncertainty 36, 245-266.

Astebro, Thomas, José Mata, \& Luís Santos-Pinto (2009). Preference for Skew in Lotteries: Evidence from the Laboratory. Working Paper.

Battalio, Raymond C., John H. Kagel, \& Komain Jiranyakul (1990). Testing Between Alternative Models of Choice under Uncertainty. Journal of Risk and Uncertainty 3, 2550.

Binswanger, Hans P. (1980). Attitudes toward Risk: Experimental Measurement in Rural India. American Journal of Agricultural Economics 62(3), 395-407.

Bleichrodt, Han, \& José Luis Pinto (2000). A Parameter-Free Elicitation of the Probability Weighting Function in Medical Decision Analysis. Management Science 46(11), 14851496.

Bardley, Ian (2003). The Representative Bettor, Bet Size, and Prospect Theory. Economics Letters 78, 409-413.

Booij, Adam S., \& Gijs van de Kuilen (2009). A Parameter-Free Analysis of the Utility of Money for the General Population under Prospect Theory. Journal of Economic Psychology, forthcoming.

Bosch-Domènech, Antoni, \& Joaquin Silvestre (1999). Does Risk Aversion or Attraction Depend on Income? An Experiment. Economics Letters 65, 265-273.

Greenwald, Anthony G. (1978). Within-Subject Designs: To Use or Not to Use? Psychological Bulletin, 314-320.

Greiner, Ben (2004). An Online Recruitment System for Economic Experiments. In: K. Kremer, V. Macho (Eds.): Forschung und wissenschaftliches Rechnen 2003. GWDG Bericht 63, Göttingen: Ges. für Wiss. Datenverarbeitung, 79-93.

Holt, Charles A., \& Susan K. Laury (2002). Risk Aversion and Incentive Effects. American Economic Review, 1644-1655.

Johansson-Stenman, Olov, Minhaj Mahmud, \& Peter Martinsson (2005). Does Stake Size Matter in Trust Games? Economics Letters 88(3), 365-369.

Kachelmeier, Steven J., and Mohamed Shehata (1992). Examining Risk Preferences under High Monetary Incentives: Experimental Evidence from the People's Republic of China. American Economic Review 82(5), 1120-1141.

Kocher, Martin G., Peter Martinsson, \& Martine Visser (2008). Does Stake Size Matter for Cooperation and Punishment? Economics Letters 99(3), 508-511.

Kühberger, Anton, Michael Schulte-Mecklenberg, and Josef Perner (2002). Framing Decisions: Hypothetical and Real. Organizational Behavior and Human Decision Processes 89(2), 1162-1175.

Lefebvre, Mathieu, Ferdinand M. Vieider, \& Marie Claire Villeval (2009). The Ratio Bias Phenomenon: Fact or Artifact? Working Paper. 
Markowitz, H. (1952). The Utility of Wealth. Journal of Political Economy 60, 151-158.

Minor, Marshall W. (1970). Experimenter-Expectancy Effect as a Function of Evaluation Apprehension. Journal of Personality and Social Psychology 15(4), 326-332.

Poulton, E. C. (1973). Unwanted Range Effects from Using Within-Subject Experimental Designs. Psychological Bulletin 80, 113-121.

Prelec, Drazen, \& George Loewenstein (1991). Decision Making over Time and Under Uncertainty: A Common Approach. Management Science 37(7), 770-786.

Sawyer, Alan G. (1975). Demand Artifacts in Laboratory Experiments in Consumer Research. The Journal of Consumer Research 1(4), 20-30.

Van de Kuilen, Gijs, Peter P. Wakker, \& Liang Zou (2006). A Midpoint Technique for Easily Measuring Prospect Theory's Probability Weighting, CREED, University of Amsterdam.

Weber, Bethany J, \& Gretchen B. Chapman (2005). Playing for Peanuts: Why is risk-seeking more common for low-stakes games? Organizational Behavior and Human Decision Processes 97, 31-46.

Wu, George, \& Richard Gonzalez (1996). Curvature of the Probability Weighting Function. Management Science 42(12), 1676-1690.

Zeiliger, R. (2000). A Presentation of Regate, Internet Based Software for Experimental Economics, http://www.gate.cnrs.fr/ zeiliger/regate/RegateIntro.ppt, GATE. Lyon: GATE. 